\title{
Study of Sustainable Settlements of Hawraman, Kurdistan, and Its Sustainable Approaches to Design of a Residential Complex in Mosha Touristic Village, Iran
}

\author{
Seidawan Hosseini (Corresponding Author) \\ Design Director, Mojda \& Associates Consulting Engineers \\ No 22, $7^{\text {th }}$ Alley, Vozara St, Tehran, Iran \\ Tel: 98-91-4412-7132Ｅ-mail: seidawan.s@gmail.com
}

\author{
Soran Shangapour \\ Iran University of Science \& Technology, Department of Architecture \\ Narmak, Tehran, Iran, 1684613114 \\ Tel: 98-91-2623-6933 E-mail: soran.shangapour@gmail.com
}

\begin{abstract}
Scholars are increasingly interested in investigating vernacular settlements to discover how they have been sustainable over time and find those utilized strategies which can be utilitarian for the present. Villages of Hawraman, are hitherto uninvestigated settlements in a mountainous region of Kurdistan. Considering their special sustainable characteristics plus climatic similarities of Hawraman region with the site of our project, a residential complex in Mosha touristic village, we studied extensively on these vernacular settlements. At first, through survey method in a descriptive - analytic way we extracted their sustainable characteristics in fields of environmental, economic and social issues. Second, we designed our practical project based on our inspirations from extracted features. At the end, we indicated our project's environmental sustainable advantages rather than surrounding complexes via comparing the rate of energy consumption. In addition, by measuring the degree of social interactions, Social sustainable advantages of our project have been proved.
\end{abstract}

Keywords: Sustainability, Vernacular, Settlement, Hawraman, Design

\section{Introduction}

Vernacular people were aware of the ways benefiting from certain climatic characteristics and controlling those that were less favorable, by choosing appropriate settling arrangements, building shapes, location, orientation and utilizing suitable local materials. Vernacular attitudes responsibly using natural resources can continue with resulting in ecological consequences. Also, a vernacular settlement is an independent local community with the similar social and cultural background. The firm and close relationship between vernacular people helps them to set up a good community, a peaceful living environment which maintains a well organized local society leading to stable socio-cultural consequences. In addition, in the vernacular society, the self-sustaining and endogenous economic pattern relied on the energy and natural resources generated inside (Dasmann, 1985) support the domestic circulation and even running of material supply chain which can contribute to self-reliant economic consequences.

In this article, as the vernacular settlements, for the first time we investigated Hawraman's villages from the climatic conditions, social context and vernacular economy perspectives. Through our article, firstly, this region has been elaborately studied by which sustainable environmental, social and economic features were derived and secondly, in a practical project whose site was similar to our case study's region, the design of a residential complex in Mosha touristic village inspired by sustainable qualities we gained through our study, presented.

Hawraman is a mountainous region located in western Iran or Iranian Kurdistan, which includes the cities of Pawe and Mariwan, and north-eastern Iraq or Iraqi Kurdistan, which includes the city of Halabja. The inhabitants of Hawraman are Kurdish people that speak Hawrami, part of the Gorani branch of the Kurdish language. "Hawraman is best known for its unique arrangement of cities and villages built along the mountain slopes of the region. Ancient religions are also practiced throughout Hawraman and the region is home to the ancient holy places of the Yarsan faith" (Wikipedia, 2010). Hawraman is one of the most mountainous regions in Iran and has a generally mild and quite pleasant climate throughout the spring and summer. Winters are long and can be very cold with heavy snowfalls.

Nowadays, the main concept of sustainable development is defined as environmental preservation, social equity and wellbeing, and economic growth. Accordingly, we discuss Hawraman's characteristics of sustainability and summarize its vernacular values from the environmental, socio-cultural and economic perspectives. We try to introduce the lessons from the timeless ways of building found in the vernacular settlements which can be useful in today's experiences. 


\section{Research Methodology}

In the theoretical research relevant concepts and definitions of sustainability and vernacular settlements were studied. In the experimental research required information was collected through survey method in a descriptive - analytic way in Hawraman's villages. The first step was to gather atmosphere, climate and environment information by means of photos, modified maps and weather data from local centers. A deeper sense in this stage derived from experiencing some main villages. In the second stage observations of social behaviors in relation with spatial characteristics and interviews with residents were carried out to find out their kinship system, cultural values, religion and social life. Scrutinizing economic situation in terms of local building material, vernacular construction method, natural resources, recycling and reusing of resources were done as well. In the next step all collected information were analyzed in view of sustainable principles to extract planning and design features useful for present sustainable settlements. In a practical project, considering many environmental and climatic similarities with Hawraman's villages, we referred to our analyzed information and adopted extracted features in our planning and design. At the end, a comparative evaluation based on energy consumption data was made to determine effects of our environmental sustainable measures used in design and construction on the rate of energy consumption.

\section{Sustainability}

The World Commission on Environment and Development (WCED, 1987) has proposed a definition of sustainability as "meeting the needs of the present without compromising the ability of future generations to meet their own needs".

"During a building's existence, it affects the local and global environments via a series of interconnected human activities and natural processes" (Kim, 1998). "By incorporating the dimension of time, or futurity, the definition of sustainable development introduced three inter connected, mutually inclusive themes, or spheres: the environment, society and economics" (Roseland, 1998) (Fig 1). Sustainable development is development that delivers environmental, economical and social services to all residents of a community, without threatening the viability of the natural, built, economic and social systems upon which the delivery of these systems depend

We need to readdress the balance between these three elements and use resources more efficiently. As in 'a better quality of life' UK Government (1999) targets:

- Social progress which recognizes the needs of everyone;

- Effective protection of the environment;

- Prudent use of natural resources; and

- Maintenance of high and stable levels of economic growth and employment.

Sustainability means protecting and continuing the genius loci, and working with within the limitations and possibilities that this requires. Sustainability of the building is sublimated to sustainability of the place. (Williamson, Radford \& Bennetts, 2003) In planning of many vernacular settlements, an appropriate climatic response was fundamental factor. Vernacular settlements often incorporated a detailed knowledge of the locality, climatically and geographically, and its capability for sustainable life.

\subsection{Environmental sustainability}

"Environmental sustainability is the ability to maintain things or qualities that are valued in the physical environment" (Sutton, 2004). It can be defined as maintaining the factors and practices that contribute to the quality of environment on a long-term basis. "Environmental sustainability requires that natural capital remains intact. This means that the source and sink functions of the environment should not be degraded. Therefore, the extraction of renewable resources should not exceed the rate at which they are renewed, and the absorptive capacity to the environment to assimilate wastes should not be exceeded. Furthermore, the extraction of non-renewable resources should be minimized and should not exceed agreed minimum strategic levels." (Gilbert, Stevenson, Girardet, Stren, 1996) Thus environmental sustainability programs have been directed to reduce exploit physical resources, the use of renewable rather than limited resources, the revise of production processes and to remove the production of toxic materials, and the preservation and restoration of natural settlements and environments.

\subsection{Economic sustainability}

Sustainability interfaces with economics through the social and ecological consequences of economic activity (Daly \& Cobb, 1989). Sustainability economics describes: ". . . a broad interpretation of ecological economics where environmental and ecological variables and issues are basic but part of a multidimensional perspective" (Soederbaum, 2008). However the concept of sustainability is much broader than the concepts of sustained yield of welfare, resources or profit margins (Hasna, 2009).

Economic Sustainability concentrates on the importance of stable economic growth. "Economic sustainability is not just about getting richer as a nation or as an individual. Gross National Product, exchange rates, inflation and profits are part of the picture; however, economic sustainability goes beyond this to involve the production, 
distribution and consumption of goods and services. It addresses issues such as the depletion of non-renewable resources, global constraints on economic growth and appropriate strategies for assigning costs to environmental pollution. The exchange of goods and services has a significant impact on the natural environment, since the environment serves as the ultimate source of raw materials and the repository for discarded materials or manufactured goods" (Dolceta, 2010). At its core, economic sustainability is about providing the various needs of a society by supplying what it needs. It is about how we choose to use our resources while taking into account how they will affect the future.

\subsection{Social sustainability}

Sustainability is not only about people being able to survive; it is also about people being able to live the best possible life. "Social sustainability requires that the cohesion of society and its ability to work towards common goals be maintained. Individual needs, such as those for health and well-being, nutrition, shelter, education and cultural expression should be met." (Gilbert, Stevenson, Girardet, Stren, 1996)

Cohen (2006) presents strategies meet human needs including: "improved education and the political empowerment of women, especially in developing countries; greater regard for social justice notably equity between rich and poor both within and between countries; and intergenerational equity."

\section{Vernacular Settlement}

Vernacular architecture, as argued by many researchers (Oliver, 1987, Knapp, 1986, Lawrence, 1983) evidences endeavors made by the users to fulfill their physical and psychological needs through a built environment. Also several researchers have discussed that the built environment can strengthen or impede human behavioral responses and that these responses can be explicitly defined using architectural remains of the past (Cox, 1972; Morril, 1974). Kelvin (1970) explains: "Much of the perceived predictability of the social environment derives in fact from awareness of history: the known or believed acceptability of an action in the past is very relevant in making it seem (the action) likely to be proper in the future."

Sustainability in the built environment can be observed in those buildings which have been with us for many decades, centuries, even millennia (Maver and Petric, 2003). Most architects in the past were acquainted with the climate and its genius loci in which they were building. They knew potentials of environmental aspects in ecological context characterizing their methods which have been examined for years and so have got optimized and sustained. This type of life style has made them spirited and independent from modern technology, and modern life style.

In any traditional settlement, buildings are related to economic needs, cultural values and social relationship of their inhabitants. Focusing on contemporary issues such as urbanization, emergency transfer, technology transfer and resources management Oliver (1987) shows that vernacular traditions are not anachronistic survivals of a vanishing world, but are in fact important to the future provision of culturally appropriate and sustainable architecture.

Qualities originated from vernacular architecture of Hawraman indicate that its architecture not only includes eco-concepts but also has a great respect for the environment. These qualities concern issues related to construction, technology, and socio-economical aspects of management. Compatible with the nature, accordant to people needs, self-efficiency, modulated structures, outward- looking are the pivotal qualities in Hawraman architecture. Hawraman's architectural principles generally cover the environment as a main part of the design, fulfill the human needs and requirements, include compatibility and harmony, and appropriately respond to climatic conditions. Climate responsive building is a possible alternative to climatic non-adapted building. It involves the application of soft measures and natural means to reduce energy consumption by design, construction and materials appropriate for a specific climate. This also has positive consequences in terms of economy as well as in terms of proper use of local resources (Gut \& kerknecht, 1993).

Hawraman has been continuously inhabited throughout the history without intervals and still presents a traditional lifestyle that gives the region a high degree of authenticity. We present many indicators which show this settlement as a sustainable complex reflects all three pillars of sustainability; environmental, economic and social dimensions. (Fig 2)

\section{Environmental sustainability of Hawraman}

Environmental sustainable achievements of Hawraman include the settlement pattern and building forms and the selection of the site are in accordance with microclimatic criteria. The shape and type of buildings and their orientation, the integration of suitable vegetation and the arrangement of the external and internal space have been carefully considered. The accurate use of natural materials, design of openings and their shading, natural cooling, passive solar heating and the well-aimed arrangement against prevailing cold winds are important supporting elements. In this section we detail strategies applied in Hawraman which have made it environmentally sustainable. 


\subsection{Wind}

Since in Hawraman the wind and the accompanying cooling are the main problem, the density and arrangement of buildings are significant in decreasing the effects of the most annoying weather conditions. In the predominantly cold climate of Hawraman, the priority is to protect against prevailing winds in cold seasons blowing from the northwest. Hawraman's settlements have been located on leeward slope of mountains toward the sunlight. The orientation of buildings varies from 15 degrees east to 12 degrees west which is the best orientation to prevent cold winds and absorb maximum amount of solar heating in this region. Trees and landforms are also used to protect against the cold winter winds. In addition, this orientation allows buildings to benefit southeastern summer winds cooled and freshen by pass on the river and green lands down the hillsides. (Fig 3)

\subsection{Sun}

In Hawraman, solar gain has been achieved easily by careful selection of materials, window placement, spatial arrangement depending on its activities, and proper terrain.

Due to the cold climate, the southern slopes have been selected to settle. The orientation of the buildings along the north-south is to maximize the penetration of the sunshine. Since in the winter sunlight shines on the earth at about 30 degrees angle, the energy of the sunlight is spread over a larger area, thus locating on slopes leads the sunlight to concentrate on a smaller area with a range of 60-80 degrees angle of shining dependent on the slope's angle of the hillsides. This kind of arrangement in the slope causes buildings to expose in minimum shading. Retaining heat is the first step in conserving energy during the winter months. Reducing surface exposure reduces heat loss through convection. Heat gets out mostly through openings such as windows where heat resistance is low, therefore openings are only placed where required either for lighting or ventilation aims. Thermal mass flooring material has been used for absorbing heat during the day and released at night. Also the heat escaped from the roof is used by the upper unit with minimum heat loss.

\subsection{Material}

Indigenous materials have been used to build the dwellings, such as stone, handmade mud bricks, straw, clay and timber that are available locally and suite the climate instead of importing materials that consume more energy and fuels.

Typically passive solar building of Hawraman incorporates materials with high thermal mass that retain heat effectively and strong insulation that works to prevent heat escape. These rural buildings are characterized by thick walls, thermal mass materials and warm colors. It's sharply cold in winter, with deep snow and average of 145 cold days, but rural buildings don't need much fossil fuel energy for heating.

The materials used for the roofs of building are main lumbers with tiny timbers perpendicular to them, that coated by straw and clay for finishing which can be found near the village with some types of waterproof greasy ingredients that work as an insulation.

The settlements have been built on a rocky ground and the stone as the main material has been used in foundations and walls. Facades built by stones absorb heat during the day and release at night. (Fig 4)

\subsection{Form}

Compactness of the form is the first measure for reducing the touch with the wind current and the orientation of buildings is important as much. The design, relative size and opening ratio of each facade have been played a major role in the energy efficiency of a building in Hawraman. In order to reducing thermal conduction, buildings tend to be very compact to minimize the surface (area- to- volume ratio) and share walls to reduce exposed surface area. The form of each building is cubic in which to gain maximum solar energy its south facade is longer than others with a larger area of openings. Windows are often sacrificed due to the essential need to preserve heat.

Because of locating in the heart of rocky mountains and merging with the terrain, buildings are highly out of from losing their internal thermal energy. Also the rocks like barriers protect the buildings from penetrating cold winds and create calm and supported area. The largest part of this supported area is next to the rocks and back to the wind so the position of the rocks determines the arrangement of the houses.

Because hot air rises, ceilings are kept very low. This results in decreasing the interior volume rather than exterior surfaces absorbing solar heat and hence the inner spaces are heated more rapidly. Another measure to keep interior spaces warm in the winter is using the flat roof in Hawraman keeping the snow on the roof as the heat isolator. (Fig 5)

Hawraman's houses have been built for the entire year. In their interior design both ventilation in summer and passive heating measures in winter have been considered. In their functional layout the most used spaces are on the side of the house orientated towards the south sunshine while the least used spaces and barns have been situated on the back which can also act as additional thermal mass. 


\subsection{Arrangement}

Hawraman's villages have been arranged in the way which results in these items:

- Maximize the potential for passive solar gain in winter

Orientation naturally plays a major role in any passive solar design. In cold climate of Hawraman, the openings have been pointed due south, directly towards the whole free heating of solar energy.

- Provide pathways with high solar heating and favorite ventilation

In Hawraman layout of pathways and orientation have important effects on offering buildings necessary sun energy in winter and also favorite wind in summer. To maximize ventilation in pathways, the primary ones have been oriented towards 15 degree east of south. It provides both night breezes and prevailing afternoon wind in summer; and solar exposure on the south elevation in winter. Main pathway orientation is within the angle of about 20 degree on either direction of the breezes.

In Hawraman, buildings have been oriented to maximize solar access in winter and to facilitate wind flow in summer. Generally, buildings have been elongated on the east-west axis. They have a simple, compact design, which minimizes the total area of perimeter walls using less energy because there is less area through which heat can leave a home.

- Placing buildings on slopes without causing overmuch solar obstruction to/by adjacent buildings

The settlements slope regularly down toward rivers and green lands. This kind of arrangements secures both pleasing views and high solar exposure from the south for the buildings without shading of adjacent buildings. In addition, the difference between temperatures of down and up of the slopes makes a pleasant stream of fresh air through the buildings in summer. All buildings are protected against backward cold wind blowing from up to down of the hillsides in winter. (Fig 6)

Arrangement of Hawraman's settlements on the slopes has originated courtyard houses which presents a new typology emanating from the topography and terrain that offers a combination of enclosed ground plan and more open upper floor. In this arrangement each roof acts as an interesting courtyard for upper unit. Each court benefits both the heat generated by south sunshine and internal heat comes from the underneath unit thereby supports lively environment.

- Fractal geometry

Sanders (1990) indicates that the final arrangement of the built environment is never random, since it is constructed through a sequence of design decisions made by people. Along with the organic growth of this village by passing time, a spatial system has been created that has made local places identifiably distinct, and at the same time, has created the comprehensive design of the settlement.

The settlement of Hawraman's villages is a spatial organization which acts as a multi-scale pattern. It consists of several typical cubes coalesced similar to the surrounding natural rocks. Its vernacular architecture is inherently organic, based on natural forms and structures and simple indigenous materials. The Buildings are able to adapt and adjust to change in order to attain a sustainable development, decrease waste and keep compatibility with the nature. It takes into account natural materials matching with the surroundings and genuine expression of the function of the building with relation of each fragment to the whole and the whole to. The geometry of this settlement emerges in evolution due to the natural need for efficiency and optimization which is the outcome of a very longtime process.

\section{Economic sustainability of Hawraman}

Energy conservation, water conservation, and material conservation are the three strategies for the sustainable economy. Each of them concentrates on a specific resource necessary for building construction and operation.

The whole of energy consumed for various activities such as construction, heating and cooling is renewable and recyclable. In addition to the above environmental sustainable strategies used in Hawraman which are the major part of energy conservation, energy-conscious site planning has played an important role in this way. Such planning allows maximizing the use of recyclable natural resources and minimizing energy consumption on the site. For example these planning through mixed-use developments, allows the people to live near their workplaces leading to less energy consumption. At the same time the distinct division of community duty and individual responsibility provide required work resources and spiritual stimulation for the optimizing local economy.

The methods used in Hawraman for supplying water resources include two main aspects. Firstly, through planting trees around the river, they attempted to control the movement of water and protect water. Secondly, they worked on collection, storage and delivery of water. Through the building of waterholes, water could be collected from the different sources such as rains, underground water and surrounding fountains.

By economizing resources, local builders have increased the use of renewable resources in the construction and operation of buildings. There is a continuous flow of natural resources in and out of a building. This flow arises with the production of building materials and continues in every part of the building's life span to build an 
environment for sustaining human well-being and activities. After a building's useful life, its local materials are reused for other buildings. In a long run, any resources entered into a building ecosystem will eventually come out from it. This is the law of resource flow conservation.

Hawraman's settlement has abundant natural resources that are essential for local production and economic development.

The natural landscape located around a Hawraman's settlement is beneficial to local inhabitants. The connection with and merge into mountains, water and forest, supplies vital energy for the existence and promotion of the settlements which enables local settlement to receive sustainable living from the heart of the nature. In addition, turning wilderness to be cultivated land and planting trees and crops along rivers is an old method used by inhabitants to support the good condition of active environment in a Hawraman's settlement.

\section{Social sustainability of Hawraman}

Place has mysterious and special meanings for the people of certain localities. Family and society are interlaced with place and land, so that people belong in various kinds of environments. Furthermore, indigenous materials and nature of local climate play a great part in organizing local culture and identity that provide a basis for sharing and participation. What is essential is maintaining existing land with all of its concepts.

Sustainable development is much about sustaining our society than about sustaining our environment. In Hawraman's settlements physical and spatial features compatible with cultural and social ones offer a sense of place which includes social interaction, sense of belonging and spiritual enrichment and fulfilling daily activity such as work resulting in sustainable social development.

According to Fleming (1985), social interaction is promoted by the presence of three variables: first, the opportunity for contact; second, proximity to others; and third, appropriate space to interact. Passageways in Hawraman's villages often lead to communal spaces that form an integral part of the settlement fabric Community courtyards serve a number of socio-cultural activities, including: children playing, gatherings during late afternoons, and celebration of social activities such as marriage festivals and religious occasions every year.

The design of settlements in Hawraman has focused on the arrangement of architectural elements, with extended attention being paid to the human factor. Its traditional settlements are characterized by taking into consideration norms deeply rooted in sustainable social principles. The organization of these traditional settlements is respectful of the equilibrium between homogeneity and heterogeneity in a social system requiring connection between domestic life and participation in economic and social life of the community. This has created continuous spaces within the constructed form of these vernacular settlements.

Based on experience in Hawraman's villages, we have found that engagement of people in these traditional communities is a warm, supportive and embracing process, which enhances the individuals' adjustment to social activities in Hawraman and, to a large extent, minimizes the difficulties associated with the absorption process of youths.

There is an interconnected between social and cultural characteristics, and rural shape of Hawraman's settlements. There is the family and clan-oriented culture and in the life style of people everybody participates in social issues and rural shape is formed based on this Contribution.

As the most important architectural element supporting such participation open spaces in this settlement constitute settings that have been designed and built to support social activities in different and extensively cultural-specific ways, and might be referred to as a "cultural landscape" (Rapoport, 1990). In Hawraman, courtyards have a double function within the spatial organization of the house. As the intermediate spaces they protect home activities and enable gatherings. They establish a relationship between public pathways and private spaces within the house in which the life is more public and open to make communication with neighborhoods. They have a flexible and practical aspect making them multi-purpose spaces for any activity that does not have its particular interior space. (Fig 7)

The anonymous builders, who often were the master builder, and the building owner, demonstrated concern with family privacy as well as with public activities and shared open spaces, thereby contributing to the social cohesion of the settlement. Plan, form and area of a specific open space in Hawraman's settlements depend on the number and inter-relations of surrounding buildings, accessibility, topography, presence of a communal public facility, social gatherings, and defense geometry.

In short, these villages arrangement presents a clear picture of the socio-physical, socioeconomic, environmental and traditional systems common in this community. It therefore suggests the relationship between the built form of the villages and the cultural qualities embodied in a traditional way of life.

\section{Hawraman's inspirations in design of Mosha}

Mosha holiday village located in mountainous region in the east of Tehran is a touristic village with a cold climate and several snowy months attractive for snow sports. The aim of this holiday village is to have people escape from the tiredness of all year professional life; get rid of the boring atmosphere of the city and support recreational activities. 
In our project, a residential complex in this touristic village, the main strategy includes design standards based on traditional sustainable design, a set of principles meant to create sustainable physical settlements that provide a combination of uses, protect environmental resources, and enhance social interactions. The strategy includes provisions to require design at the human scale by providing for organic pathways, clear delineations of public spaces, continuity between open and close spaces, and connections between the settlement and the nature.

This project is intended to provide for the diversity necessary for recreational village life, while maximizing the interactions among related spaces and minimizing the negative impacts of rigid planning and arrangement. It includes following uses:

- Residential units for a broad range of housing types

- Destination hotel for tourists (Fig 8)

- Small-scale retail spaces to provide uses that meet the retail and service needs of a residential complex

Considering many environmental and climatic similarities with Hawraman's villages, we referred to our understandings and findings through studying sustainable distinctions of Hawraman and utilized its creativities and plans.

Direction of prevailing cold winds, average annual temperature, annual rainfall, topography and terrain, latitude, rate of humidity are among similar features convinced us to make effective use of the strategies offered by vernacular settlement of Hawraman in the field of a sustainable planning and design.

In the following we explain planning and design policies by which our residential complex benefits sustainable advantages:

- Site Selection and orientation

Site selection is not a formal section of a design process. Right site decisions, however, can contribute to a profound impact on a project's success. Site selection is a decision that affects the organization, arrangement, function, proficiency, and sustainability of a project. Our decision and its goals in this way:

Locating and arranging our complex on the slope of a hillside dominant on Damavand River oriented toward the southeast resulted in providing residential units with the maximum solar energy and protecting them against unfavorable prevailing cold winds. Also the favorite wind in summer freshened by pass on the river down the slope of the hillside, can ventilate houses naturally. (Fig 9)

In a comparative evaluation, we sought to determine whether our environmental sustainable measures used in design and construction of the project has optimized the energy consumption. In order to investigate the role of proper orientation toward southeast on the rate of energy consumption, a comparison made between our project and a neighbor residential complex located on the west. We selected one unit of each complex and gathered their energy consumption data inserted in gas and electricity bills of all months. Based on collected data, comparative diagrams of energy consumption for cold and mild months were drawn. The examined units arranged with different orientations had the same area, height, construction material, and windows size. According to this comparison, we observed unsuited orientation and arrangement resulted in higher rate of energy consumption and required the unit of neighbor residential complex use more cooling and heating mechanical devices. (Fig 10, 11)

Also, we can obviously see a high degree of social interactions and socially live neighborhoods. Similar to what we learned from intermediate spaces of Hawraman, open and attractive places on the roofs of houses in our project contribute to enhance neighborhood-based social engagements.

Pathways and circulation spaces in our project are publicly owned. The physical dimensions of these places and their special characteristics are our important design elements in making opportunities for contact. In order to enhance the level of proximity to others pedestrian routes have been designed to provide access to residential buildings, and since the layout of these is irregular, the resulting route system is crooked. This pattern has been adopted Hawraman's method in arrangement of pathways. On the contrary in other complexes in Mosha regular and rigid nets of circulation spaces has resulted in poor social interactions. (Fig 12)

Communal gathering open spaces in this project defined by surrounding buildings, act as appropriate spaces to interact. Residential buildings open to alleyways, passageways, and other "convex, non linear, tortuous" (Hillier, Hanson \& Peponis, 1987) spaces in the settlement layout have been formed in the way that encourage social interactions. Hillier (1987) calls this feature "continuous constitution" of space by building.

- Form

Basic spatial elements of this complex include closed elements such as dwellings define open spaces, alleys and the like, which knit the whole settlement together into a continuous system. This relationship between these closed and open elements forms an overall spatial arrangement.

Compactness, fractal geometry and cubic units, east-west elongation, flat and low roofs, embedding into the ground and open terraces are key factors we learned from sustainable form of Hawramn's settlements and utilized in our design. (Fig 13) 
- Material

We selected local high thermal mass materials mostly local stones with dark color in the construction of the project. In addition to the ecological benefits, lower energy and costs and easier construction are useful consequences of this decision. From another viewpoint as a result of using natural materials, the sense of belonging and harmonic connection with the nature, have made our complex environmentally sustainable.

\section{Conclusion}

The vernacular settlement is a dynamic process of development over time by the collective actions of people. Hawraman's settlement can be recognized as a living organism which is the result of centuries of optimization of material utilizing, building techniques and environmental considerations. Being mountainous and isolated, this vernacular settlement has conserved old types of dwellings more than other areas of Kurdistan. Through studying and investigating of various characteristics, we showed why vernacular settlements of Hawraman are sustainable. This sustainability includes three significant principles, environmental maintaining the factors and practices that contribute to the quality of environment on a long-term basis, economic and social sustainability providing the various needs of a society by supplying what it needs, and social sustainability requiring that the cohesion of society and its ability to work towards common goals be maintained. Profoundly examining the possibilities of implementing local vernacular strategies can be useful for the present. Consideration this fact, we tried to put into action what we learned from Hawraman in a professional project. In the design of a residential complex in touristic village of Mosha, inspiration from extracted features led to a more sustainable complex rather than surrounding ones. As a proof to our claim, according to a comparative evaluation we made, we observed unsuited orientation and arrangement can result in higher rate of energy consumption up to 2.3 times more than our climatically planned arrangement in coldest month.

\section{References}

Cohen, J.E. (2006). Human Population: The Next Half Century. In D. Kennedy, (Ed.), Science Magazine's State of the Planet. London: Island Press. pp. 13-21.

Cox, K. R. (1972). Man, Location, and Behavior: An Introduction to Human Geography. New York: John Wiley.

Daly, H. \& Cobb, J. (1989). For the common good: redirecting the economy toward community, the environment, and a sustainable future. Boston, MA: Beacon Press

Dasmann, R. F. (1985). Achieving the sustainable use of species and ecosystems, Landscape Planning, 12 Fleming, R., Baum, A., \& Singer, J.E. (1985), Social Support and the Physical Environment, Social Support and Health. In S. Cohn, \& S.L. Syme, (Eds.). Orlando, FL: Academic Press.

Gilbert, R., Stevenson, D., Girardet, H., and Stren, R. (1996). Making cities work: The role of local authorities in the urban environment. London: Earthscan.

Gut, P., \& kerknecht, D. A. (1993). Climate Responsive Building: Appropriate Building Construction in Tropical and Subtropical Regions. SKAT Publications.

Hasna, A.M. (2009). Sustainability and Economic Theory: an Organism in Premise. The International Journal of knowledge, culture, and Change Management, 9 (11), 1-13.

Hillier, B., Hanson, J., \& Peponis, J. (1987). Syntactic Analysis of Settlements, Architecture \& Behavior, 3(3), 217-231.

Kelvin, P. (1970). The Bases of Social Behaviour. London : Holt, Reinehart and Winston Ltd.

Kim, J-J., \& Rigdon, B. (2000). Sustainable architecture module: Introduction to sustainable design. National Pollution Prevention Center for Higher Education. [Online] Available: http://www.umich.edu/ (July 8, 2010).

Knapp, R. G. (1986). China's Traditional Rural Architecture. A Cultural Geography of the Common House. Honolulu : University of Hawaii Press.

Lawrence, D. (1983). The Interpretation of Vernacular Architecture, Vernacular Architecture, 14, 19-29.

Maver. T., \& Petric, J. (2003). Sustainability: real and/or virtual?, Automation in Construction, 12, 641-648.

Morril, R. L. (1974). The Spatial Organization of Society. Balmont, CA: Wadsworth.

Oliver, P. (1987). Dwellings. the House across the World. University of Texas Press, Austin.

Rapoport, A. (1990). On Regions and Regionalism, Pueblo Style and Regional Architecture, In N, Markovich, (Ed.), New York: Van Nostrand Reinhold. pp. 272-288.

Roseland, M. (1998). Toward Sustainable Communities: Resources for Citizens and Their Governments. New Society Publishers.

Sanders, D. (1990). Behavioral Conventions and Archaelogy: Methods for The Analysis of Ancient Architecture, Domestic Architecture And The User of Space, S, Kent (Ed.), Cambridge: Cambridge University Press. pp. 43-72. 
Soederbaum, P. (2008). Understanding Sustainability Economics. London: Earthscan.

Sutton, P. (2004). A Perspective on environmental sustainability? A paper for the Victorian Commissioner for Environmental Sustainability. [Online] Available: http://www.green-innovations.asn.au/ (August 22, 2010).

WCED, (1987). Our Common Future, Brundtland Report. Oxford: Oxford Press.

Williamson, T., Radford, A., \& Bennetts, H. (2003). Understanding Sustainable Architecture. London and New York: Spon Press.

http://en.wikipedia.org/wiki/Hawraman, (June 7, 2010)

http://www.dolceta.eu/, (August 23, 2010)

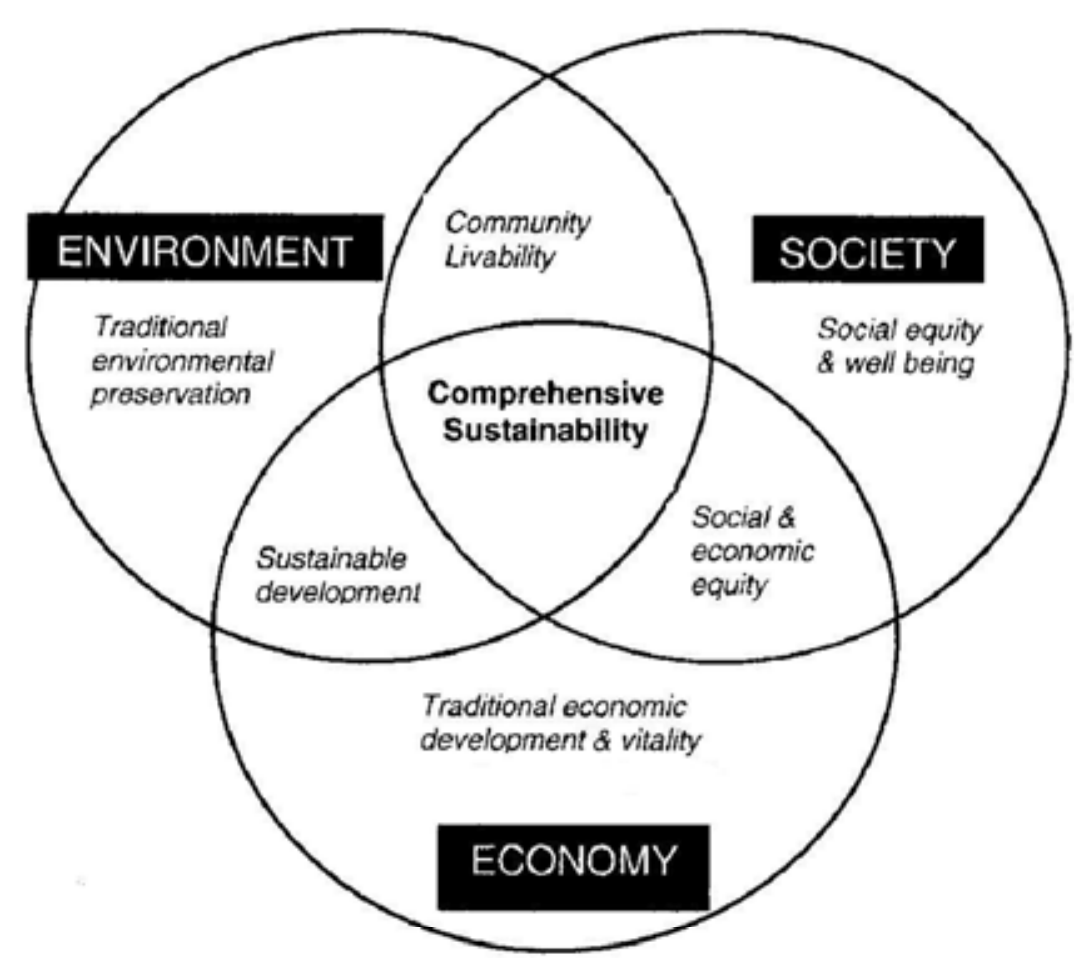

Figure 1. The three spheres of sustainability Source: Diagram adapted from: www.tcst.org 


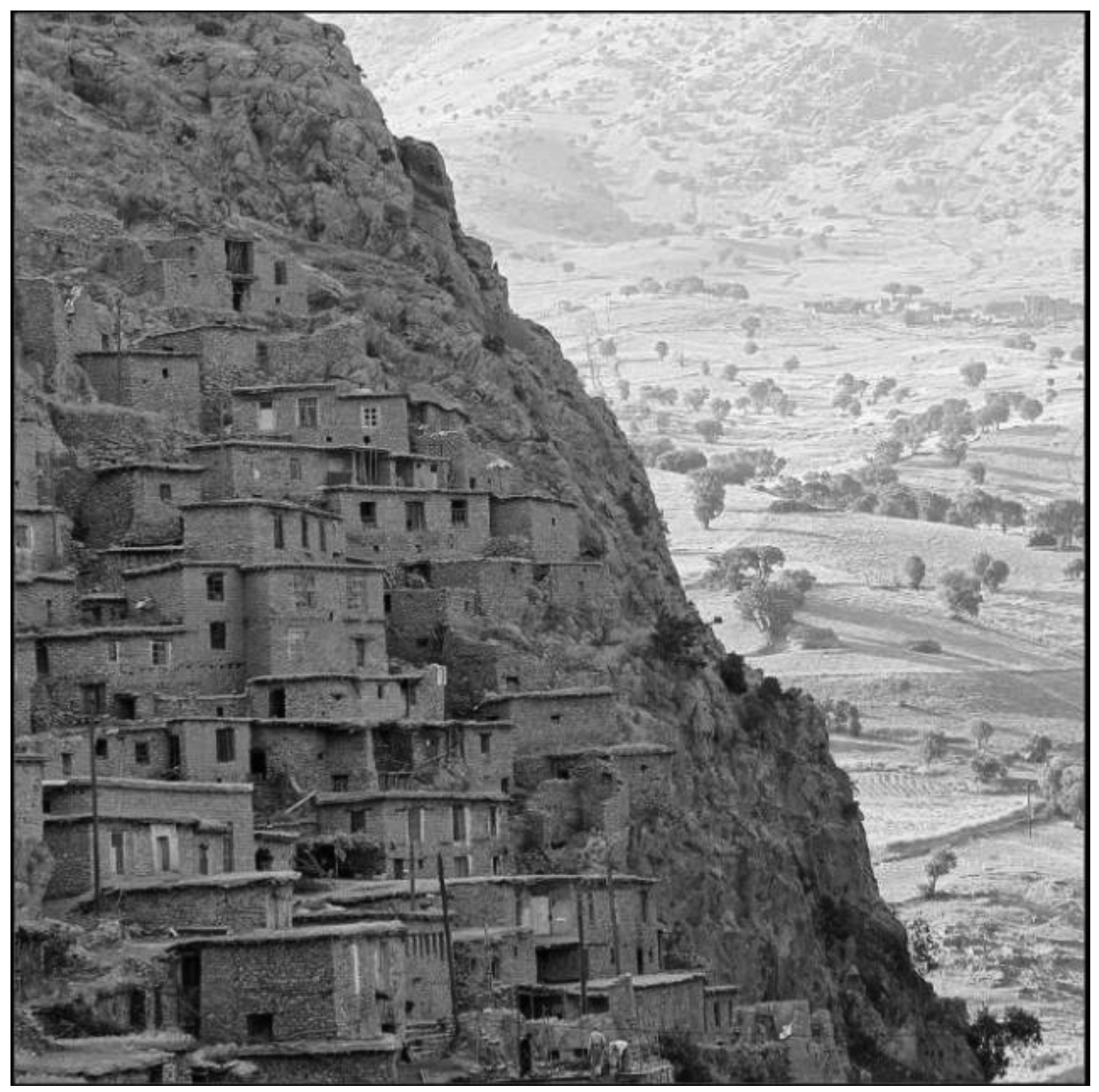

Figure 2. View of a village in Hawraman nearby the city of Marivan. Integration between Hawraman's settlements and the nature

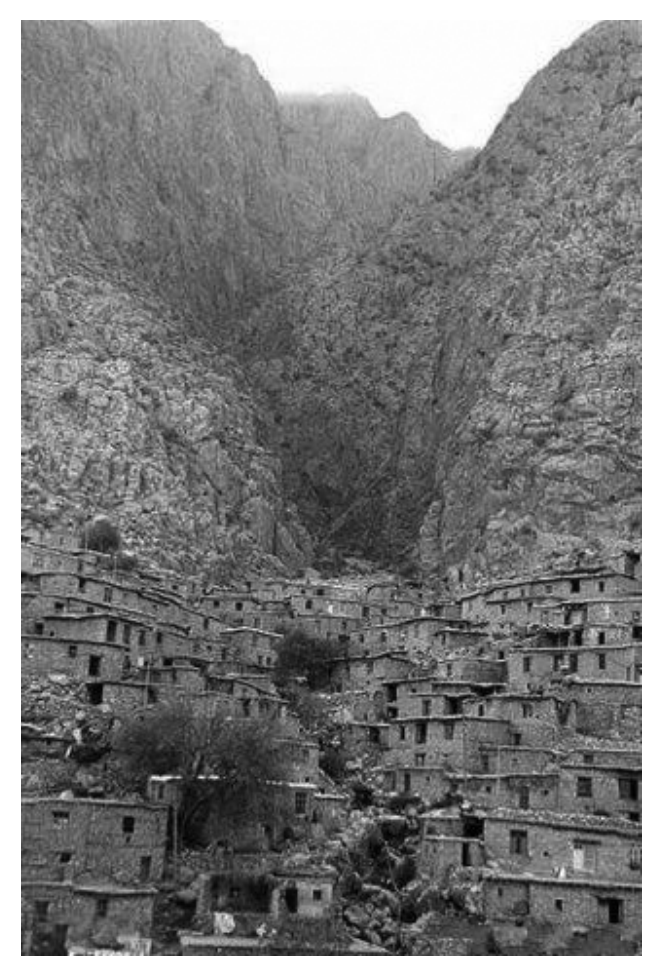

Figure 3. View of a village in Hawraman Takht, appropriate arrangement protecting against cold winds 


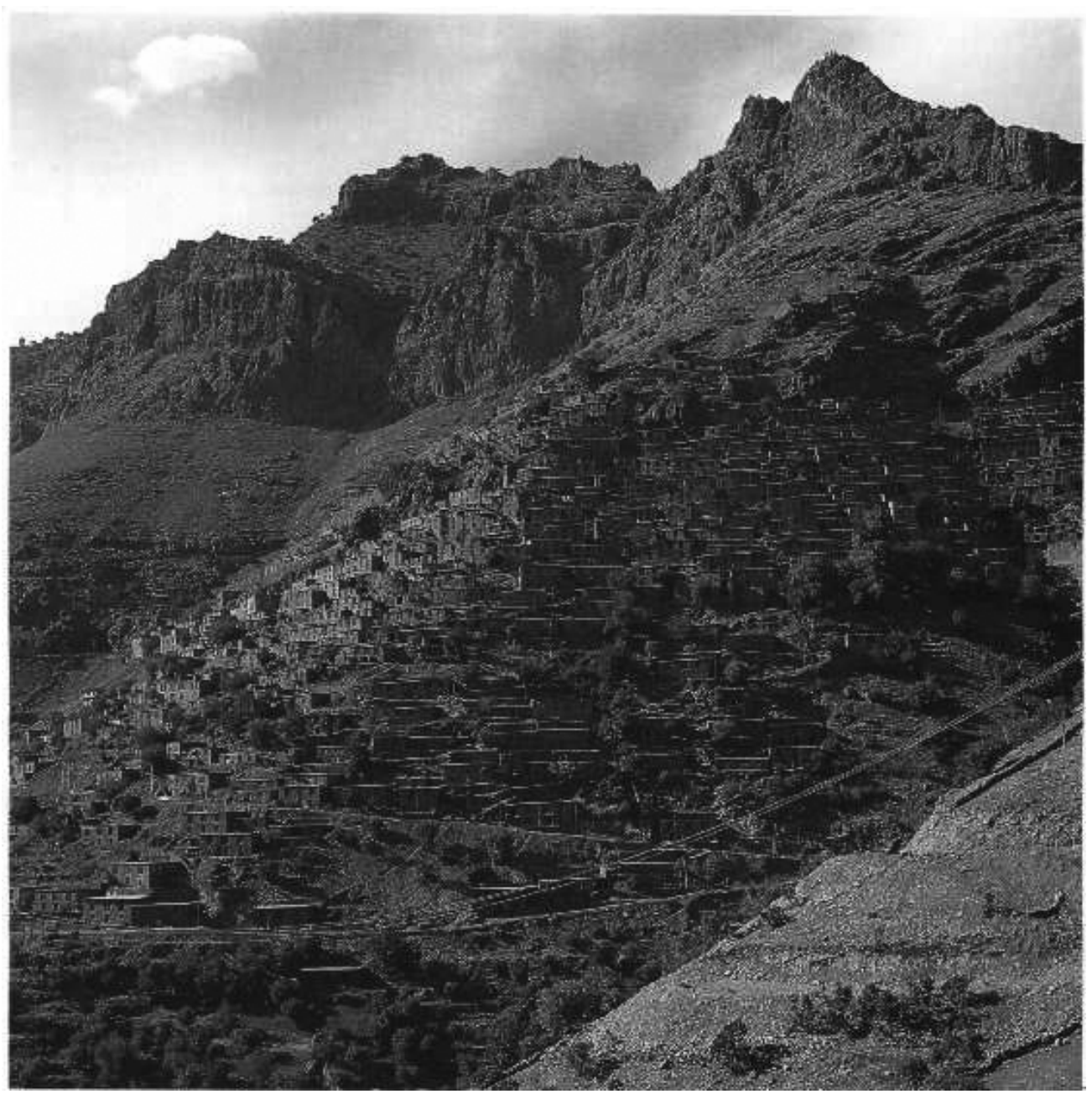

Figure 4. View of a village in western Hawraman, Using local materials

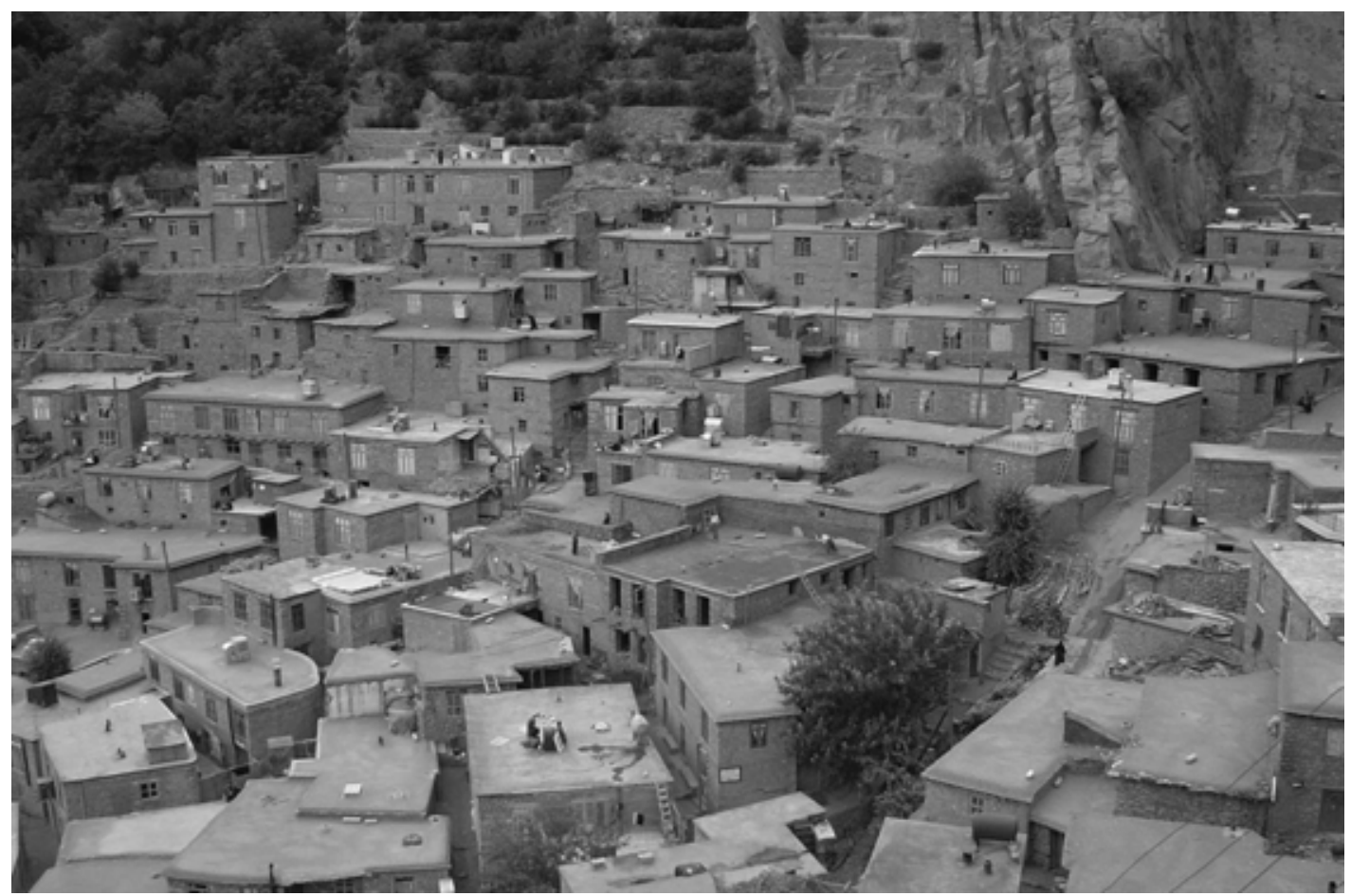

Figure 5. View of a village in Hawraman, Cubic forms and flat roofs 


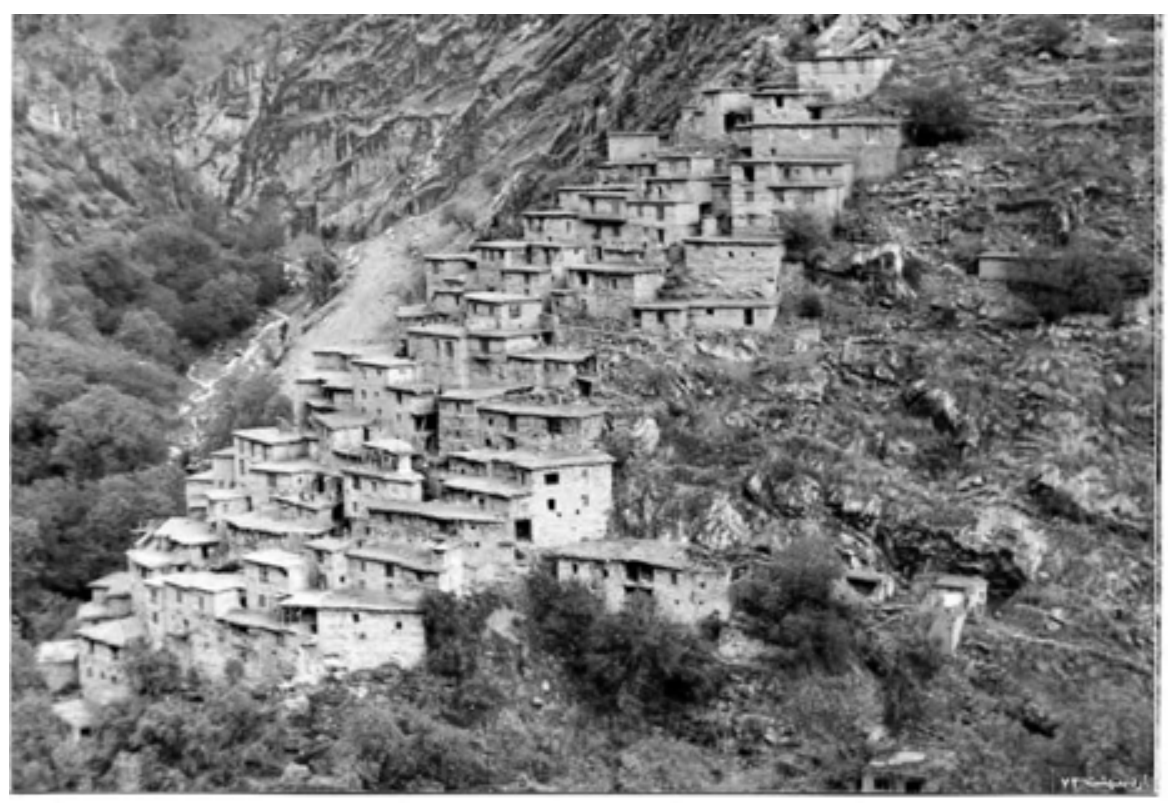

Figure 6. View of a village in eastern Hawraman sloping regularly down toward the river and green lands

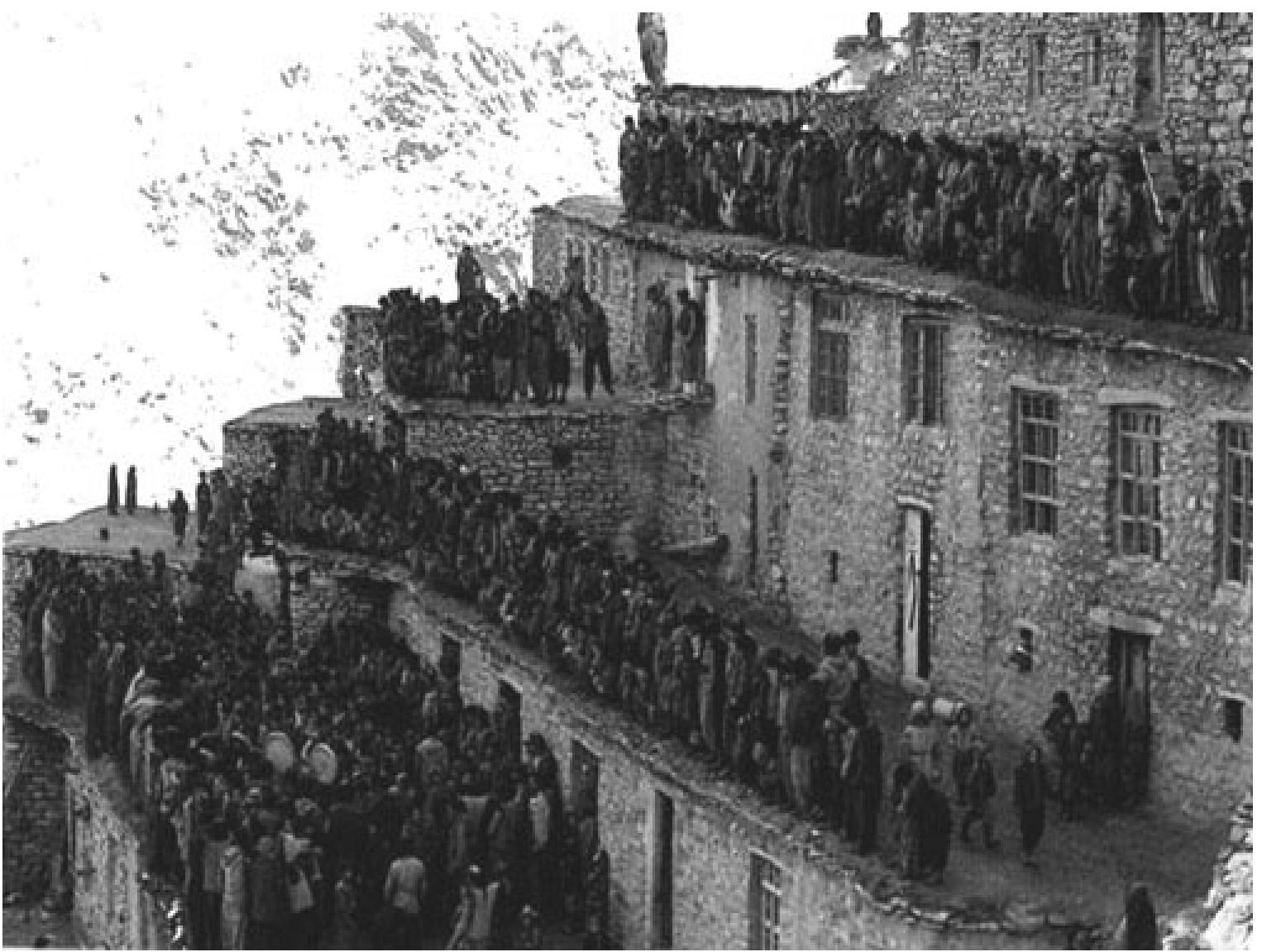

Figure 7. View of a village in Hawraman Takht. Social gatherings in a rite 


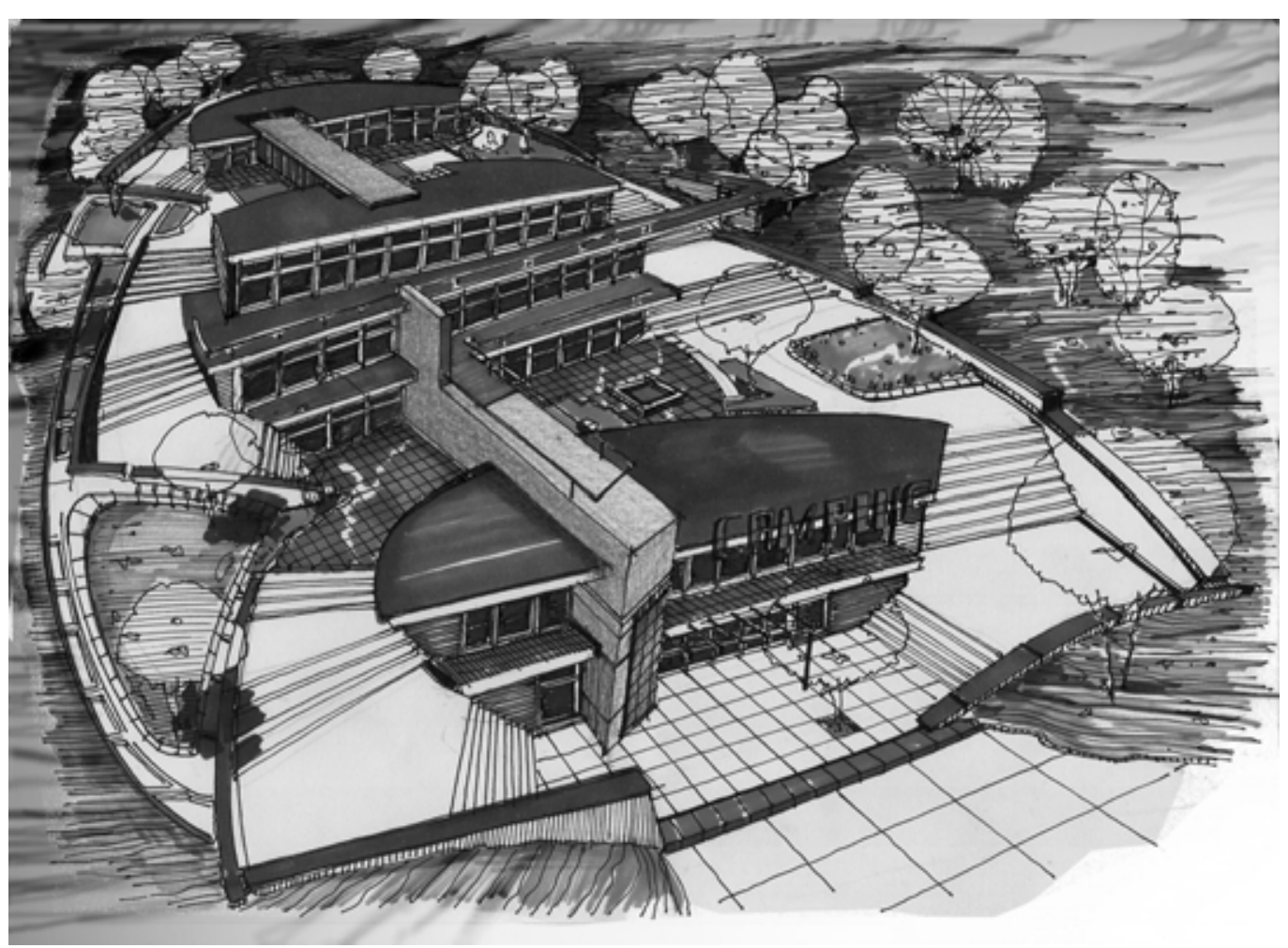

Figure 8. View of a destination hotel nearby the residential complex

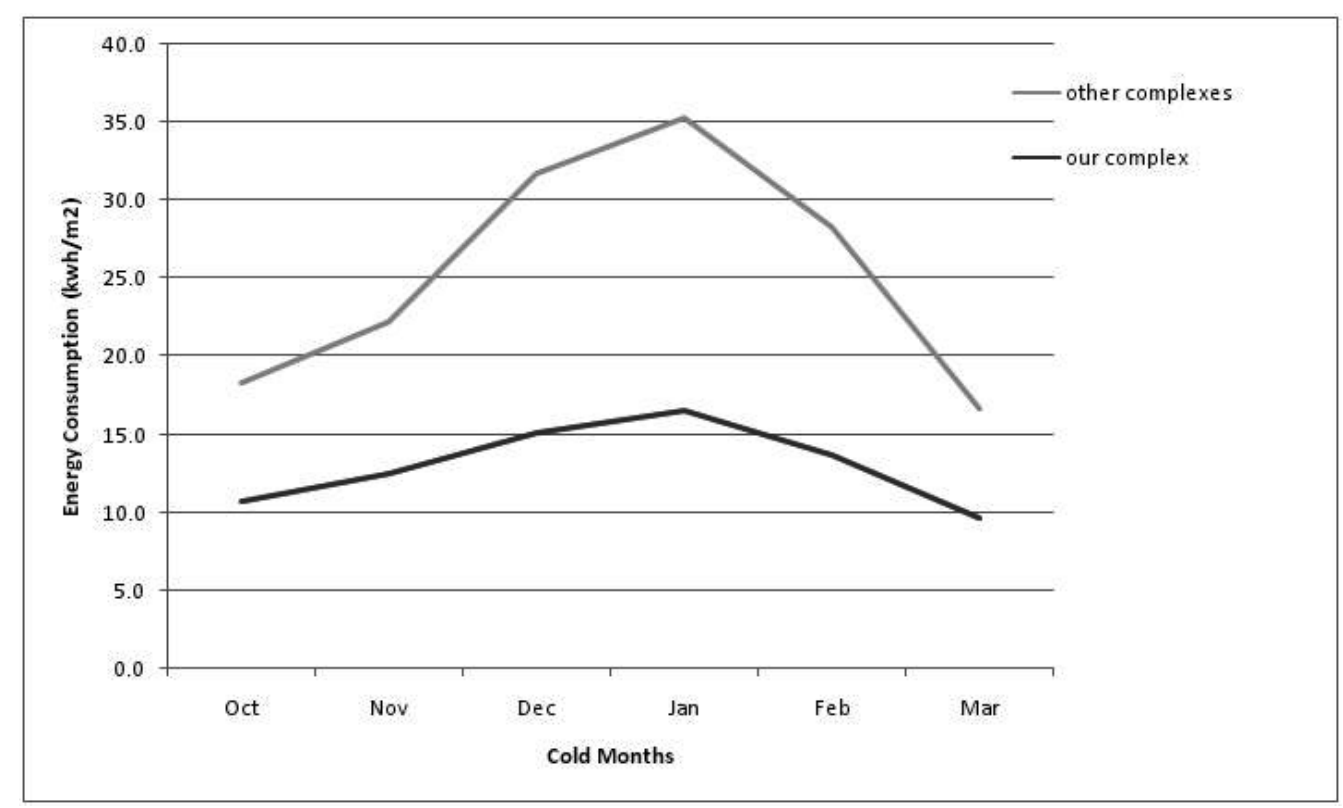

Figure 9. Energy (heating, electricity, lighting, etc) consumption difference between our complex and others in cold months 


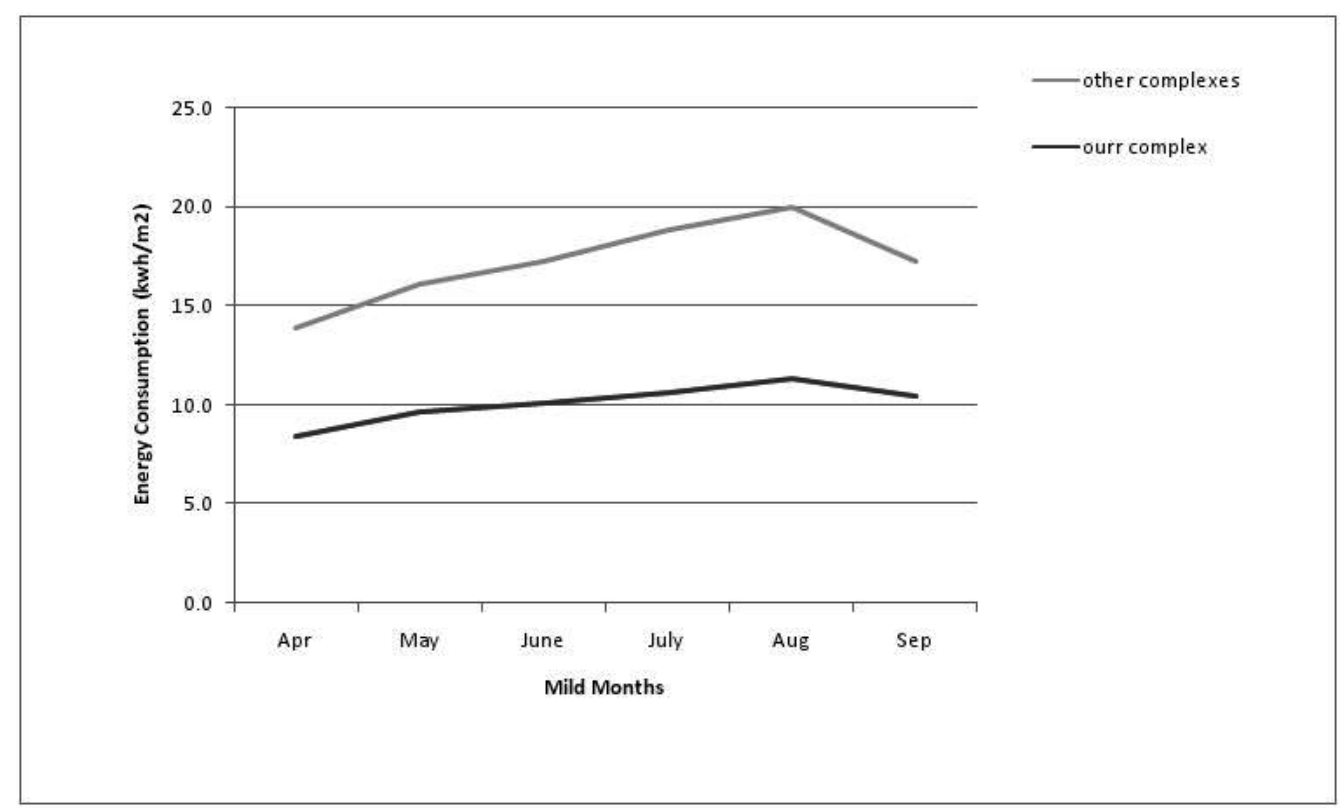

Figure 10. Energy (cooling, electricity, lighting, etc) consumption difference between our complex and others in mild months

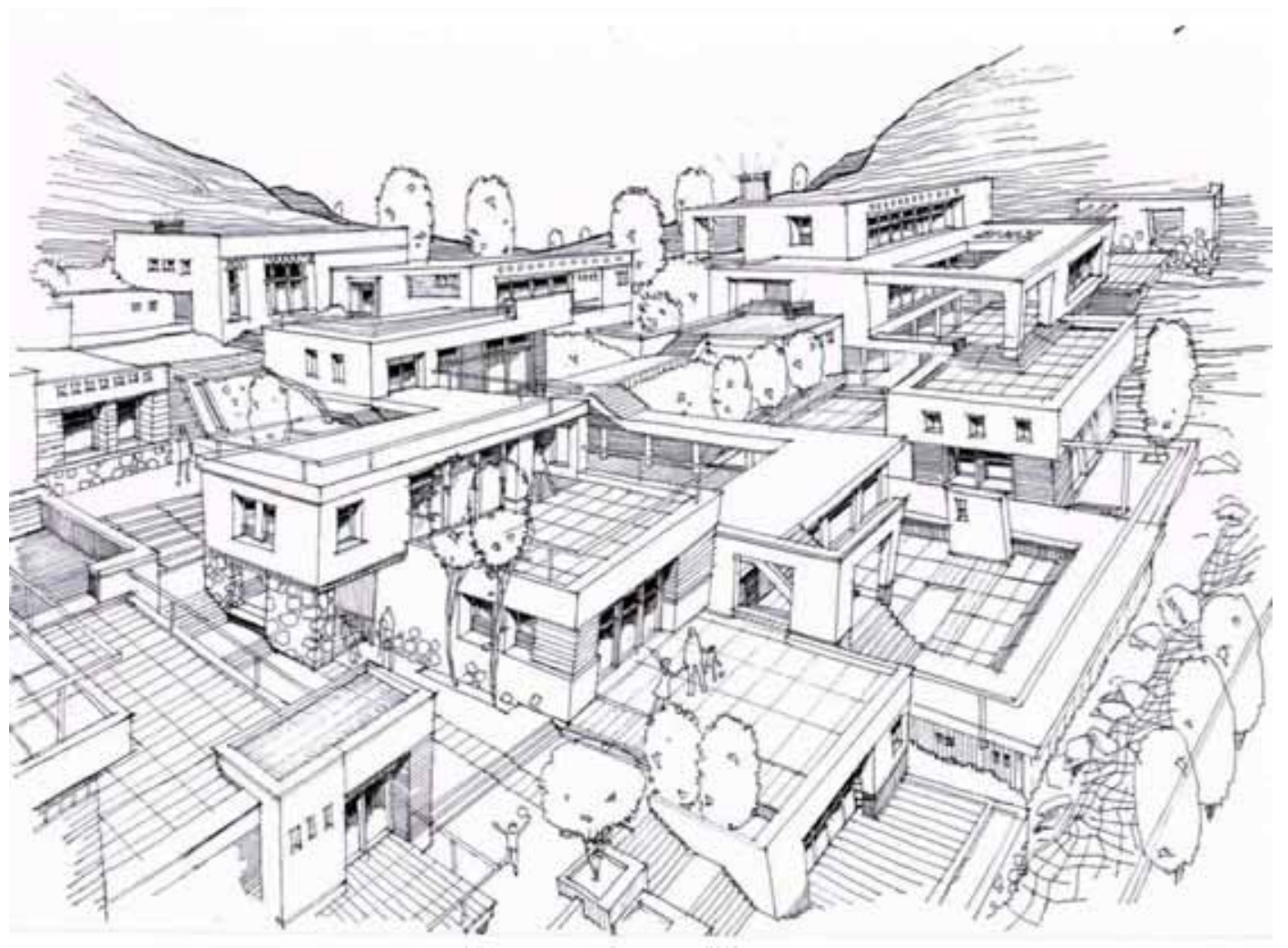

Figure 11. A residential complex in Mosha recreational village 


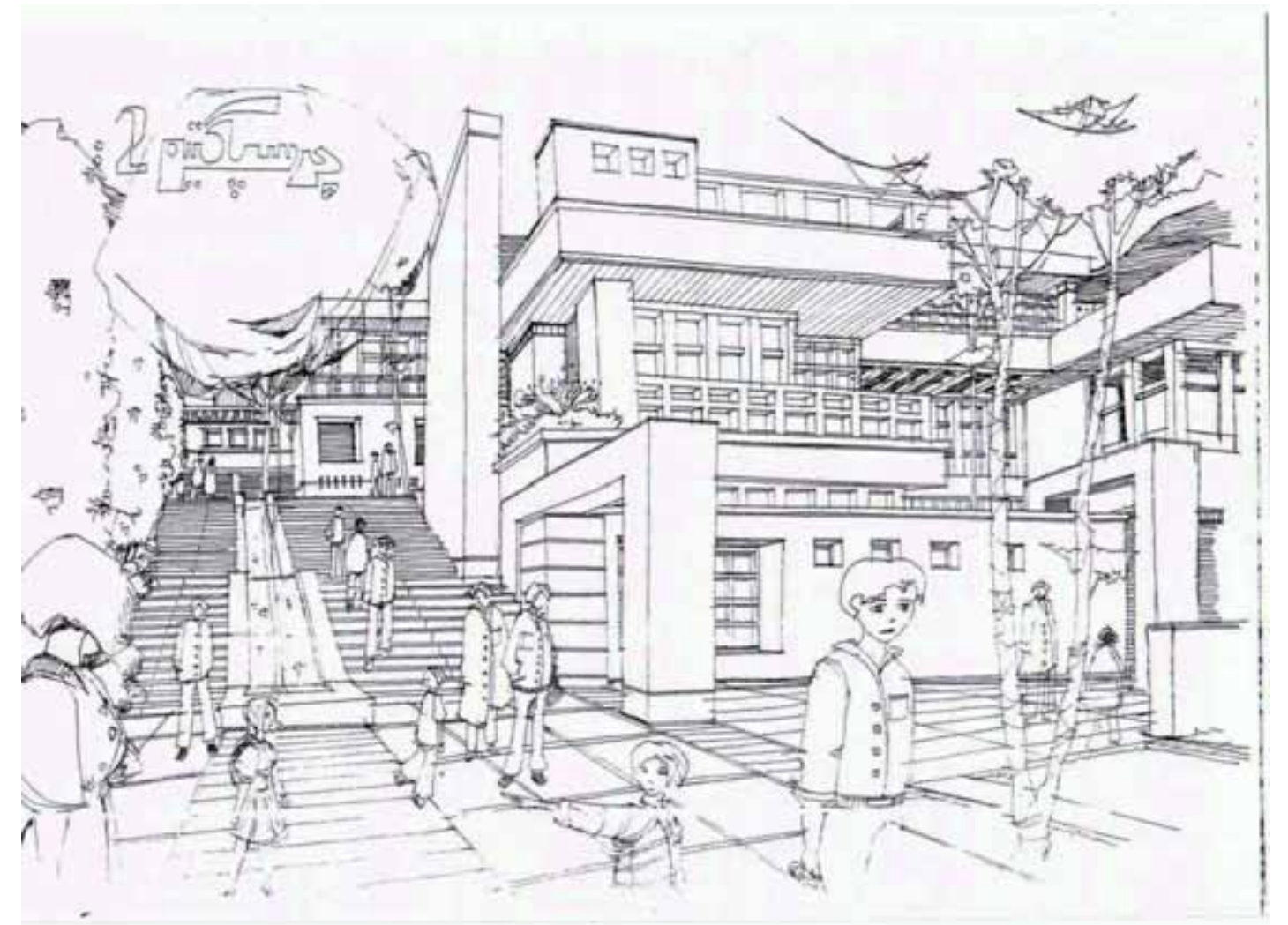

Figure 12. Close view of the residential complex in Mosha recreational village

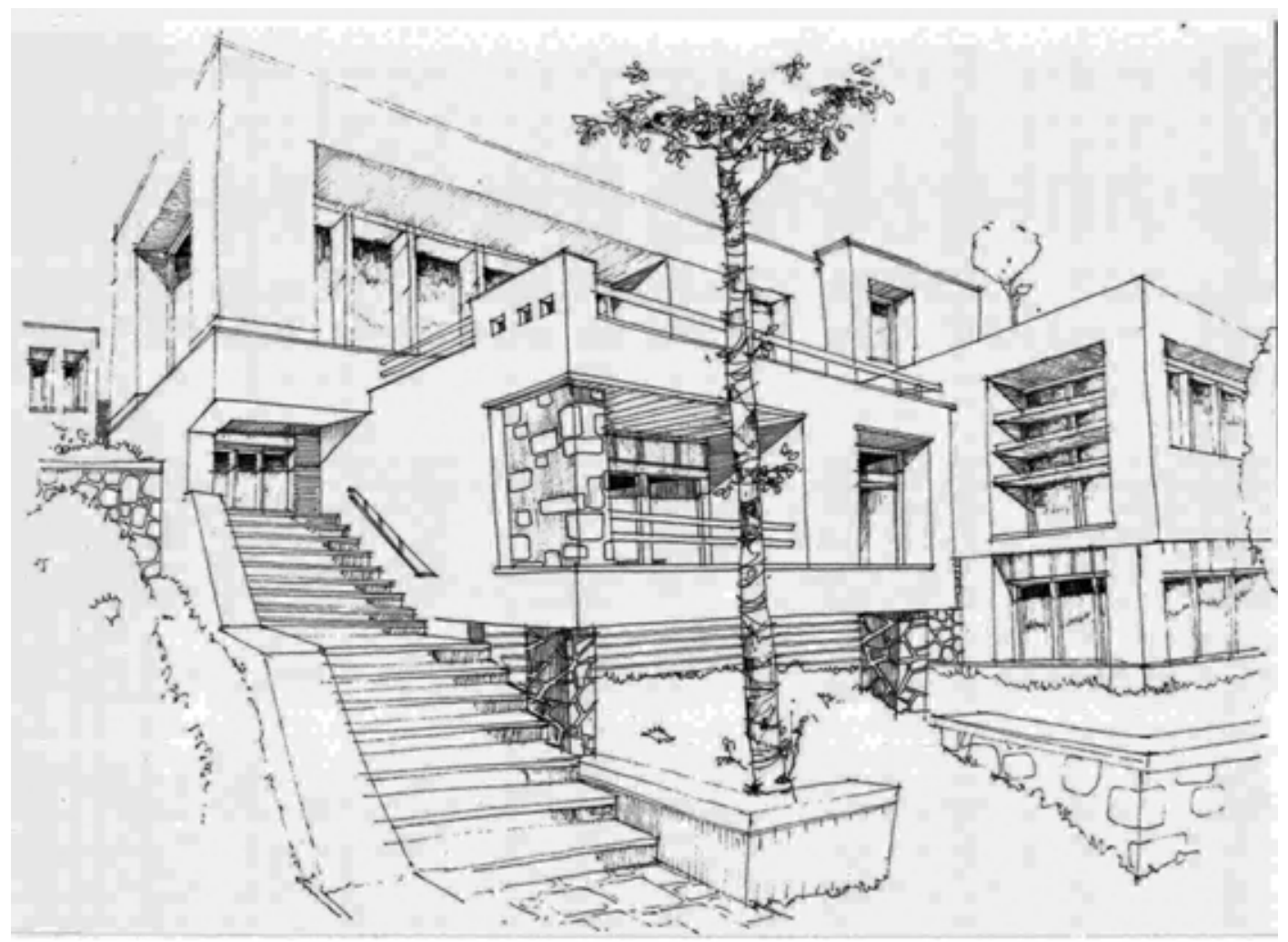

Figure 12. Close view of the residential complex in Mosha recreational village 